ARTICLE

\title{
Metal chalcogenide hollow polar bipyramid prisms as efficient sulfur hosts for Na-S batteries
}

\author{
Muhammad Kashif Aslam (10 1, leuan D. Seymour ${ }^{2}$, Naman Katyal ${ }^{2}$, Sha Li ${ }^{3}$, Tingting Yang ${ }^{1}$, Shu-juan Bao , \\ Graeme Henkelman (i) ${ }^{2 \otimes} \&$ Maowen Xu (iD ${ }^{1 凶}$
}

Sodium sulfur batteries require efficient sulfur hosts that can capture soluble polysulfides and enable fast reduction kinetics. Herein, we design hollow, polar and catalytic bipyramid prisms of cobalt sulfide as efficient sulfur host for sodium sulfur batteries. Cobalt sulfide has interwoven surfaces with wide internal spaces that can accommodate sodium polysulfides and withstand volumetric expansion. Furthermore, results from in/ex-situ characterization techniques and density functional theory calculations support the significance of the polar and catalytic properties of cobalt sulfide as hosts for soluble sodium polysulfides that reduce the shuttle effect and display excellent electrochemical performance. The polar catalytic bipyramid prisms sulfur@cobalt sulfide composite exhibits a high capacity of $755 \mathrm{mAh} \mathrm{g}^{-1}$ in the second discharge and $675 \mathrm{mAh} \mathrm{g}^{-1}$ after 800 charge/discharge cycles, with an ultralow capacity decay rate of $0.0126 \%$ at a high current density of $0.5 \mathrm{C}$. Additionally, at a high mass loading of $9.1 \mathrm{mg} \mathrm{cm}^{-2}$, sulfur@cobalt sulfide shows high capacity of $545 \mathrm{mAh} \mathrm{g}^{-1}$ at a current density of $0.5 \mathrm{C}$. This study demonstrates a hollow, polar, and catalytic sulfur host with a unique structure that can capture sodium polysulfides and speed up the reduction reaction of long chain sodium polysulfides to solid small chain polysulfides, which results in excellent electrochemical performance for sodium-sulfur batteries.

\footnotetext{
${ }^{1}$ Key Laboratory of Luminescence Analysis and Molecular Sensing (Southwest University), Ministry of Education, School of Materials and Energy, Southwest University, Chongqing 400715, PR China. ${ }^{2}$ Department of Chemistry, The University of Texas at Austin, Austin, TX 78712, USA. ${ }^{3}$ State Key Laboratory of Physical Chemistry of Solid Surface, Collaborative Innovation Center of Chemistry for Energy Materials, Department of Chemistry, College of Chemistry and Chemical Engineering, Xiamen University, Xiamen 361005, China. ${ }^{凶}$ email: henkelman@utexas.edu; xumaowen@swu.edu.cn
} 
$\mathrm{R}$ esearch in energy storage and energy conversion systems is important to develop technologies that can contribute to resource sustainability and long-term development of human society by studying new electrode materials with high energy and power densities. Group IA alkali-metal sulfur (Li-S and $\mathrm{Na}-\mathrm{S}$ ) batteries have been investigated extensively due to their high energy density and energy storage properties ${ }^{1-7}$. Na-S batteries have charge/discharge mechanisms similar to Li-S batteries that involve a two-electron redox per sulfur atom, which is why its theoretical sulfur capacity will also be $1672 \mathrm{mAh} \mathrm{g}^{-16-8}$. Similar to Li-S, Na-S batteries offer high energy density, power density and energy efficiency, and are nontoxic with good cycle life. An advantage of $\mathrm{Na}-\mathrm{S}$ batteries over $\mathrm{Li}-\mathrm{S}$ batteries is the low cost and high abundance of the raw materials that make them suitable for large-scale production ${ }^{8,9}$. In the last decade, two operating temperature ranges of $\mathrm{Na}-\mathrm{S}$ batteries have been studied: high-temperature $270-350{ }^{\circ} \mathrm{C}$ and room temperature. At high operating temperatures, the molten sodium metal and sodium polysulfides (NaPSs) are known to be corrosive and can cause vigorous reactions between the molten sodium and molten sulfur through a broken separator film ${ }^{10}$. Safety concerns are very important for energy storage technologies, as exemplified by the recent fire incident at NGK Insulator Ltd. related to a $\mathrm{Na}-\mathrm{S}$ battery ${ }^{8}$. In contrast, at ambient temperatures, $\mathrm{Na}-\mathrm{S}$ batteries are safer, more durable and offer lower operating costs and thus have been studied by many research groups ${ }^{9-12}$. Nevertheless, Na-S batteries face problems, including: (1) the dissolution of NaPSs in the electrolyte causing high capacity fade; (2) formation of sodium metal dendrites during charging that inevitably lead to short-circuits; and (3) the low utilization rate of the sulfur cathode, that constrains the electrochemical reactions to a certain distance from the current collector and limits the cell capacity.

Specifically, at room temperature, $\mathrm{Na}-\mathrm{S}$ batteries have some crucial problems that need to be addressed. Firstly, the poor conductivity of the active material, $\mathrm{S}$, results in slow electrochemical reaction kinetics and lower $S$ utilization ${ }^{13,14}$. Secondly, $\mathrm{Na}-\mathrm{S}$ batteries have a higher volume strain rate than $\mathrm{Li}-\mathrm{S}$ batteries, which makes the cathode of $\mathrm{Na}-\mathrm{S}$ batteries susceptible to collapse $^{15}$. Finally, NaPSs produced during the multi-step discharge reaction have high solubility and reactivity, which makes it easier for NaPSs to diffuse toward the $\mathrm{Na}$-anode and cause a severe "shuttle effect", resulting in a significant decrease in capacity ${ }^{5}$. Nevertheless, some progress has been made to improve the conductivity of $\mathrm{S}$ cathodes and speed up the reaction kinetics of $\mathrm{Na}-\mathrm{S}$ batteries at room temperature. For example, carbon materials can be combined with $S$ to improve the cathodic electrical conductivity, including carbon spheres ${ }^{16}$, carbon nanofibers $^{17}$, carbon nanotubes ${ }^{18}$, carbon cloths ${ }^{19}$, etc. These materials not only improve the utilization rate of $\mathrm{S}$, but also control the volume strain due to their rich porous structure. Zhang et al. assembled a $\mathrm{Na}-\mathrm{S}$ battery using $\mathrm{S}$-interconnect hollow nanospheres of carbon (S@Con-HC) as a cathode, but it displays limited cycling stability ${ }^{5}$. Zhang et al. constructed a Na-S battery using porous carbon microspheres (S-PCMs) as the cathode but it also suffers from inferior redox activity ${ }^{18}$. Although the $S / C$ hybrid designs can greatly improve the utilization of sulfur, it should be pointed out that it is very difficult to achieve full electrochemical reversibility using nonpolar carbon structures as $S$ hosts. Nonpolar carbon-based materials have weak interactions with polar NaPSs and cannot effectively prevent the diffusion of NaPSs, resulting in NaPSs $\left(\mathrm{Na}_{2} \mathrm{~S}_{x}, 4 \leq x \leq 8\right)$ moving between the anode and cathode (the shuttle effect), which results in parasitic redox reactions on the surface of the $\mathrm{Na}$-metal anode (Fig. 1b).

In recent years, polar materials, including $\mathrm{MnO}_{2}{ }^{20}, \mathrm{TiO}_{2}{ }^{21}$, alpha- $\mathrm{Ni}(\mathrm{OH})_{2}{ }^{22}$, and $\mathrm{SiO}_{2}{ }^{23}$ have been shown to strongly interact with polysulfides and effectively bind them to the cathode to attain reversible electrochemical cycling. Nevertheless, most of the metal oxides and hydroxides are semiconductors with poor electronic conductivities, resulting in low rate capabilities. Suitable sulfur hosts should have both strong polysulfide attraction and good electronic conductivity ${ }^{24}$. Moreover, since the interaction between solid polar (non-hollow) materials and NaPSs is created only on the surface as single-layer chemical adsorption, such solid structures can only capture a small amount of NaPSs; NaPSs away from the surface can still dissolve in the electrolyte and shuttle between the electrodes (Fig. 1c) ${ }^{25}$. A promising approach is to construct a polar hollow architecture, which can physically block the path of outward diffusion, thus encapsulating the polysulfides in the wide inner space of the cathode (Fig. 1d). As a result, hollow polar S hosts can more efficiently block NaPSs diffusion than other structures, such as nanoparticles and flakes. In addition to the above strategies, the use of host materials that effectively catalyse the conversion of long-chain $\mathrm{NaPSs}\left(\mathrm{Na}_{2} \mathrm{~S}_{x}\right.$, $4 \leq x \leq 8$ ) to short chain NaPS is a particularly promising approach to inhibit NaPSs diffusion ${ }^{26}$. Due to the insulating properties of sulfur and NaPSs, the electrochemical discharge/ charge process is sluggish. For non-catalytic hosts such as carbon, carbon nanotubes, carbon nano fibers, carbon hollow nanospheres, and double-shell carbon microspheres, the conversion of NaPSs is slow and the intermediate polysulfides can easily dissolve into the electrolyte. However, due to the use of the catalytic S host, such as electronically conducting transition metal sulphide hosts can effectively act as electrocatalysts to accelerate the redox kinetic of long chain NaPSs $\left(\mathrm{Na}_{2} \mathrm{~S}_{x}, 4 \leq x \leq 8\right)$ and efficiently convert to solid phase $\mathrm{S}$ and $\mathrm{Na}_{2} \mathrm{~S} / \mathrm{Na}_{2} \mathrm{~S}_{2}$ (Fig. 1d). Consequently, the use of catalytic materials as sulfur carriers in the construction of advanced $\mathrm{Na}-\mathrm{S}$ batteries could be a promising approach.

Here, inspired by the above encouraging strategies of hollow, polar and catalytic S hosts, we synthesized a unique architecture, hollow polar bipyramid prism catalytic $\mathrm{CoS}_{2} / \mathrm{C}$ as a sulfur carrier (S@BPCS) (Fig. 1a). S@BPCS is an efficient host for solid-phase S and NaPSs, because every bipyramid prism structure has a wide hollow cavity for sulfur loading and for the entrapment of NaPSs. When used as a cathode in Na-S batteries, S@BPCS exhibits good electrochemical performance with stable cycling and rate capability that suggests maximum utilization of $\mathrm{S}$, strong binding of NaPSs, is catalytically active for converting long-chain polysulfides into small chain polysulfides, and it delivers good electrical conductivity. Here, the charge/discharge mechanisms of S@BPCS for reversible battery reactions have been studied using in situ Raman spectroscopy, in situ XRD, ex situ TEM, ex situ Xray photoelectron spectroscopy (XPS), and density functional theory (DFT) calculations.

\section{Results}

Synthesis and characterization of sulfur hosts. Inspired by the advantages of hollow, polar, interweaving surface structure, and catalytic activity of $\mathrm{Co}$ for $\mathrm{Na}-\mathrm{S}$ batteries, we synthesized hollow polar bipyramid prism cobalt chalcogenides and used them as sulfur hosts. The bipyramid prisms of cobalt were synthesized by simple reflux methods (see "Methods" section). The X-ray diffraction (XRD) pattern confirmed the formation of $\mathrm{C}_{10} \mathrm{H}_{16} \mathrm{Co}_{3} \mathrm{O}_{11}$ and was attributed to the standard PDF of JCPDS\#22-0582, as shown in Supplementary Fig. 1.

In order to study the structure and morphology of the asprepared precursor, field emission scanning electron microscopy (FESEM) (Fig. 2a, b) and transmission electron microscopy (TEM) (Fig. 2c and Supplementary Fig. 2) along with energy dispersive spectroscopy (EDS) elemental mapping was performed (Fig. 2d). The bipyramid Co prisms were converted into hollow bipyramid Co/C prisms. To confirm the phase purity and hollow 

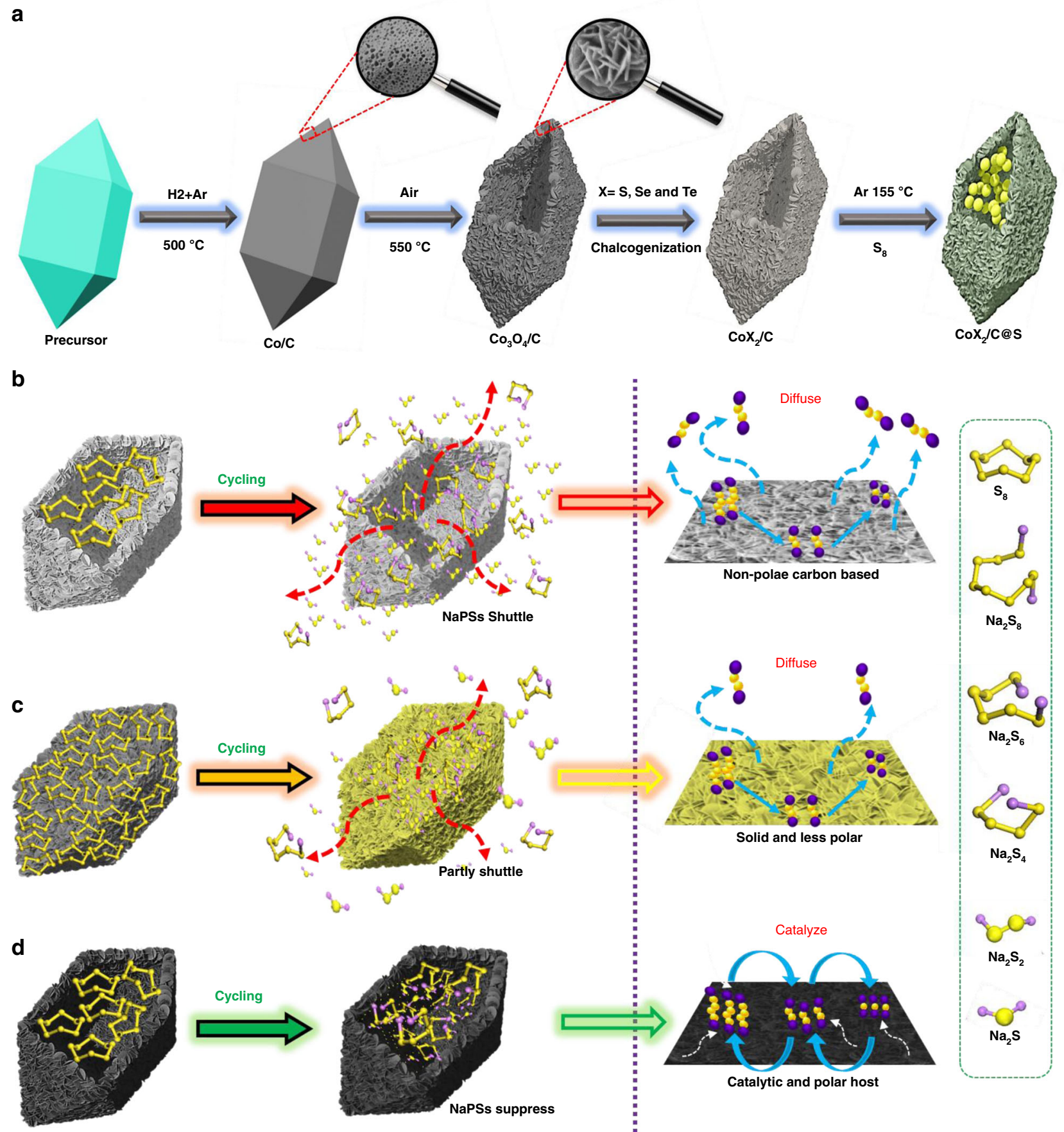

Fig. 1 Synthesis of chalcogenides and illustration of polysulfide diffusion effect. a Synthesis of metal chalcogenide S@BPCX composites. b Nonpolar hollow carbon host. $\mathbf{c}$ Diffusion of NaPSs in solid nonpolar host and $\mathbf{d}$ suppression of NaPSs in hollow polar/catalytic host.

interior of $\mathrm{Co} / \mathrm{C}, \mathrm{XRD}$ and $\mathrm{TEM}$ tests were performed (Supplementary Fig. 3 and Supplementary Fig. 4b), respectively. Afterward, the $\mathrm{Co} / \mathrm{C}$ hollow prisms were converted into $\mathrm{Co}_{3} \mathrm{O}_{4} / \mathrm{C}$ (BPCO). The phase purity and morphology of BPCO were investigated by XRD and FESEM, as shown in Supplementary Fig. 5 and Fig. 2e, f, respectively. FESEM images of BPCO show that it has a unique hierarchical surface with interweaving platelike structures. To confirm the elemental composition, EDS mapping was performed, as shown in Supplementary Fig. 6. Furthermore, BPCO was converted into $\mathrm{CoS}_{2} / \mathrm{C}$ (BPCS), $\mathrm{CoSe}_{2} / \mathrm{C}$ (BPCSE) and $\mathrm{CoTe}_{2} / \mathrm{C}$ (BPCTE) by an ion-exchange method, their formation and phase purity was confirmed by XRD analysis as represented in Supplementary Figs. 7-9 and their chemical compositions was confirmed by EDS elemental mapping as shown in Supplementary Figs. 10-12, respectively. Figure $2 \mathrm{~g}$ shows a FESEM image of BPCS representing a distinctive morphology with a hierarchical surface.

Furthermore, the chemical composition and morphology of BPCS was confirmed by TEM; Fig. $2 \mathrm{~h}$ shows that the bipyramid hollow prisms of BPCS have $376 \mathrm{~nm}$ hollow wide space to accommodate sulfur and polysulfides within it. In addition, HRTEM and single-crystal spot transmission electron diffraction patterns confirm the synthesis of BPCS, as shown in Fig. 2i-k. The Brunauer-Emmett-Teller (BET) surface area of BPCS is 

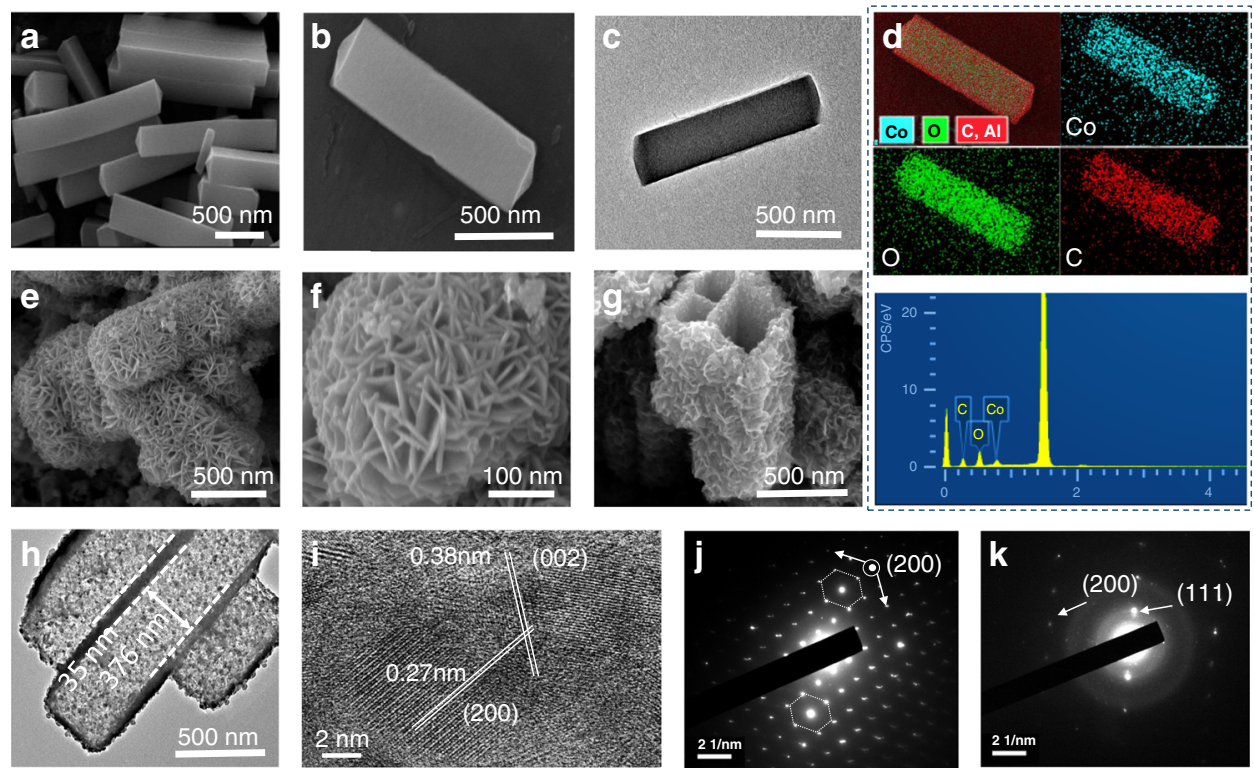

Fig. 2 Illustration and characterization of bipyramid like prisms of co-precursor. $\mathbf{a}$, b FESEM images. $\mathbf{c}$ TEM image and $\mathbf{d}$ EDS elemental mapping of coprecursor. e, f FESEM images of BPCO. $\mathbf{g}$ FESEM image. $\mathbf{h}$ Low-resolution TEM image. $\mathbf{i}$ High-resolution TEM image and $\mathbf{j}$, $\mathbf{k}$ SAED patterns of BPCS.
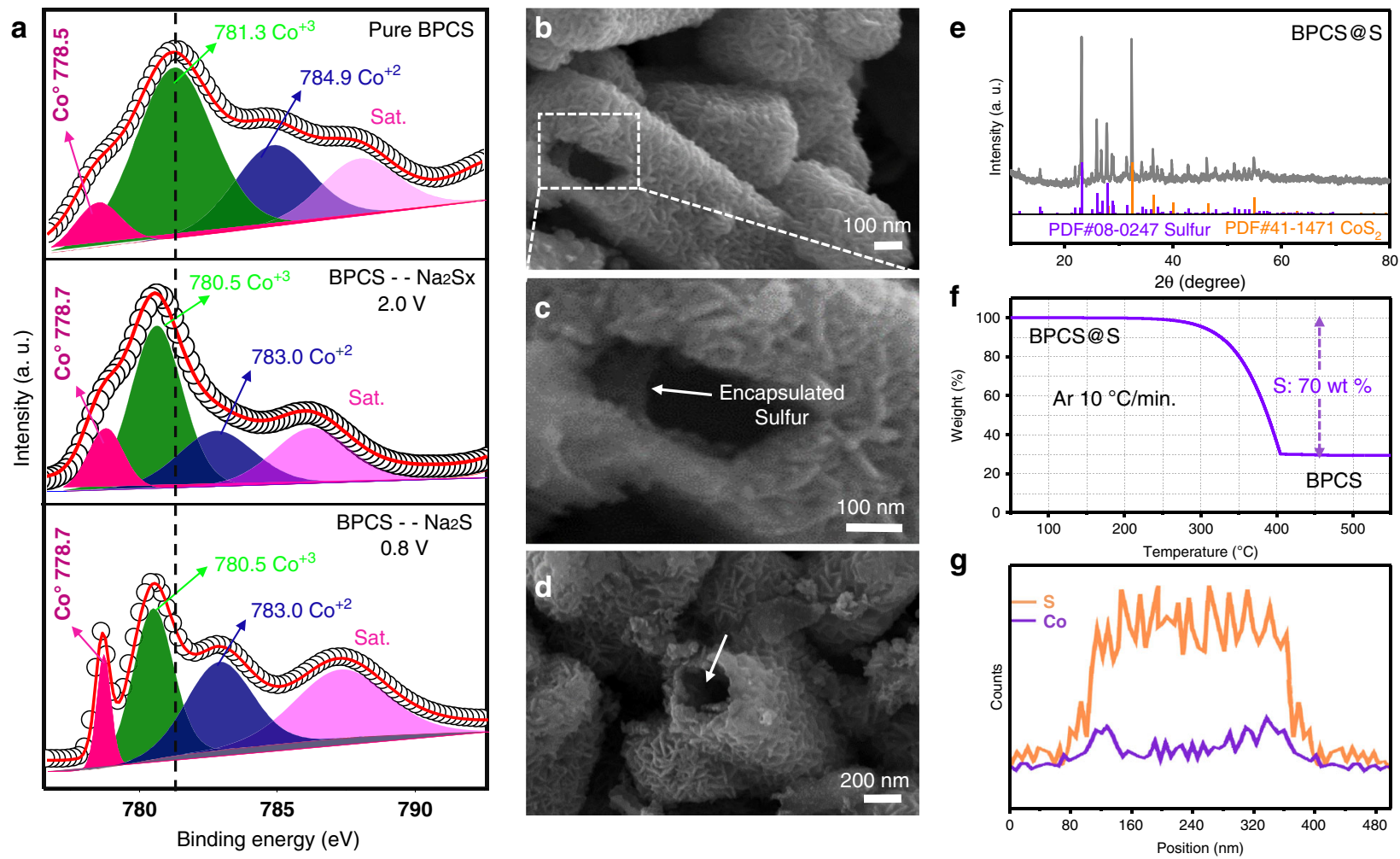

Fig. 3 Characterization of bipyramid prism like S@BPCS composite. a Comparison of the high resolution XPS of Co 2p3/2 of pure S@BPCS, after discharge at $2 \mathrm{~V}$ and $0.8 \mathrm{~V}$. b-d FESEM images of S@BPCS composite. e XRD pattern. $\mathbf{f}$ TGA curve and $\mathbf{g}$ EDS line scan of S@BPCS.

$119.9 \mathrm{~m}^{2} \mathrm{~g}^{-1}$ and the hysteresis loop is of type $\mathrm{H} 4$ indicates the physisorption isotherm of type I, which conforms to IUPAC, demonstrating that BPCS is composed of uniform slit-like pores, representing microporous structure, as shown in Supplementary Fig. 13. Finally, sulfur was injected into the hollow prisms using a melt-diffusion method to achieve the S@BPCS composite, as shown in Fig. 3b-d. Figure $3 \mathrm{c}$ shows that sulfur efficiently steamed into the inner side of the prism wall and there is no sulfur agglomeration on the hierarchical surface of the BPCS, indicating sulfur removal from the surface at $190^{\circ} \mathrm{C}$. The XRD pattern of the S@BPCS composite confirms the cubic sulfur loading in the hollow bipyramid with interweaving plates like surfaced BPCS (Fig. 3e). An EDX line scan was recorded to examine the position of sulfur; Fig. 3g clearly shows sulfur efficaciously loaded inside the hollow prism. Furthermore, a thermogravimetric analysis (TGA) was performed to measure the content of loaded sulfur in the hollow prism S@BPCS composite. The mass of loaded sulfur was calculated using Fig. $3 \mathrm{f}$ 
and Supplementary Fig. 14, and determined to be as high as $64.5 \%$.

Electrochemical performance of Na-S battery. To investigate chemical interactions between BPCS and NaPSs, ex situ XPS analysis was employed, as shown in Fig. 3a. To understand the chemical interactions between the host BPCS and NaPSs we made three different samples for ex situ XPS as pure BPCS and two discharged cell samples at 2.0 and $0.8 \mathrm{~V}$. The binding energies of cobalt decreases as electrons transfer from NaPSs to BPCS when discharged at 2.0 and $0.8 \mathrm{~V}$, which is attributed to the strong chemical interaction between BPCS and NaPSs during the discharge process. This type of interaction between BPCS and NaPSs suppresses the shuttle effect, increases the cycling stability, and improves the capacity.

To examine the electrochemical storage properties and NaPSs redox reactions of polar catalytic BPCS and other metal chalcogenides, cyclic voltammetry (CV) and galvanostatic charge/discharge (GCD) plots were recorded as shown in Supplementary Fig. 15. Impressively, the CV plot of S@BPCS exhibits comparatively higher current density and peak potential because of its high electrical conductivity as well as catalytic and high polar nature that results in enhanced electrical conductivity and strong chemical interaction between BPCS and NaPSs. The CV curves of the S@BPCS composite exhibit two reduction peaks. The peak at $2.12 \mathrm{~V}$ corresponds to the reduction of sulfur to longchain Na-polysulfides $\left(\mathrm{Na}_{2} \mathrm{~S}_{X}, X \geq 4\right)$ and the other reduction peak at a lower potential, $1.6 \mathrm{~V}$, corresponds to the further reduction of long-chain polysulfides to short-chain Na-polysulfides $\left(\mathrm{Na}_{2} \mathrm{~S}_{X}\right.$, $X \leq 4)$. The anodic scan also exhibits two oxidation peaks, at 2.05 and $2.6 \mathrm{~V}$, which are attributed to the oxidation of short-chain polysulfides to long-chain polysulfides and sulfur ${ }^{19}$. The redox processes indicate high reversibility of the cell reactions.

The GCD of the S@BPCS composite was also evaluated. Higher capacity and longer potential plateaus suggest that the BPCS sulfur host can assist as an electrocatalyst to accelerate the cathode redox reactions and enhance the utilization of active sulfur. Figure 4a shows the 1st, 2nd, and 50th charge-discharge profiles of the S@BPCS composite electrode with $4.4 \mathrm{mg} \mathrm{cm}^{-2}$ mass loading and $29 \mu \mathrm{m}$ thickness (Supplementary Fig. 16). The 1st reversible discharge capacity is $1347 \mathrm{mAh} \mathrm{g}^{-1}$ at a high current density of $0.5 \mathrm{C}$ and the profiles clearly show long plateaus. The plateaus at higher potentials are due to the formation of the solid-liquid state of sulfur and NaPSs, while, the plateaus at lower potential are due to the reduction of longchain NaPSs $\left(\mathrm{Na}_{2} \mathrm{~S}_{8}, \mathrm{Na}_{2} \mathrm{~S}_{6}\right.$, and $\left.\mathrm{Na}_{2} \mathrm{~S}_{5}\right)$ to short-chain polysulfides $\left(\mathrm{Na}_{2} \mathrm{~S}_{3}, \mathrm{Na}_{2} \mathrm{~S}_{2}\right.$, and $\left.\mathrm{Na}_{2} \mathrm{~S}\right)$. The cycling performance of the S@BPCS composite shows excellent stability (Fig. 4c), the specific capacity of 2nd discharge was $755 \mathrm{mAh} \mathrm{g}^{-1}$ and after 350 cycles, it was $701 \mathrm{mAh} \mathrm{g}^{-1}$ at a high current density of $0.5 \mathrm{C}$ with $98.5 \%$ Coulombic efficiency. The coulombic efficiency of all the metal chalcogenide@S electrodes are given in Fig. 4f. The capacity decay per cycle is $0.0126 \%$, which is significantly lower than anything previously reported in the literature (Supplementary Fig. 17). It is worth noting that pure BPCS has a negligible contribution to the capacity under the same charge-discharge conditions (Supplementary Fig. 18). The cycling performance of other metal chalcogenides is shown in Supplementary Fig. 19. In addition, the Celgard polymer separator was used to test the cycle performance of BPCS@S and KB@S, and compared with the glass fiber separator in the supporting information (Supplementary Fig. 20). When using the glass fiber separator instead of the Celgard polymer separator, diffusion of polysulfides is slowed because of its thickness and porous structure, resulting in good electrochemical performance.
The rate performance of the sulfur cathodes was also measured. Figure $4 \mathrm{~b}$ shows the rate performance of S@BPCS at different current densities from 0.5 to $3 \mathrm{C}$. The cathode S@BPCS composite exhibits capacities as high as $755,565,475,415,382$ and $349 \mathrm{mAh} \mathrm{g}^{-1}$ at current densities of $0.5,1,1.5,2,2.5$, and $3 \mathrm{C}$, respectively. Compared to other metal chalcogenides, the S@BPCS composite has a higher rate capability, as shown in Supplementary Fig. 21. Also, when the current density was switched back to the initial value, the S@BPCS composite exhibits a high reversible capacity of $727 \mathrm{mAh} \mathrm{g}^{-1}$ as compared to other metal chalcogenides (486, 432 and $399 \mathrm{mAh} \mathrm{g}^{-1}$ for S@BPCO, S@BPCSE, and S@BPCTE, respectively). To the best of our knowledge, the S@BPCS composite has remarkable rate capabilities as compared with state-of-the-art materials previously reported in the Na-S battery literature, as shown in Fig. 4h $\mathrm{h}^{16,21,27-39}$.

In order to take full advantage of the high theoretical capacity of the $\mathrm{S}$ cathode, a high mass loading is a key factor to scale up the practical application of the Na-S battery. However, high loading of insulating sulfur will facilitate the shuttling of NaPSs and the capacity decay will be more serious with a decrease in the utilization rate of active sulfur and a decrease in the capacity of active sulfur. Therefore, it is still a great challenge to optimize the performance of high sulfur loading in Na-S batteries. Previous studies have reported that only batteries with a capacity greater than $4 \mathrm{mAh} \mathrm{cm}^{-2}$ can exceed commercial LIBs ${ }^{40}$. In addition to this, considering that the voltage of the $\mathrm{Na}-\mathrm{S}$ battery is lower than that of SIBs, a higher areal capacity is required for the former system. In this work, with the mass loading of $4.4 \mathrm{mg} \mathrm{cm}^{-2}$, the capacity of the S@BPCS cathode was more than $4 \mathrm{mAh} \mathrm{cm}^{-2}$. To verify the superiority of the S@BPCS cathode, batteries with high mass contents of 7.3 and $9.1 \mathrm{mg} \mathrm{cm}^{-2}$ were cycled at $0.5 \mathrm{C}$ (Fig. 4d, e). An initial areal capacity of $6.24 \mathrm{mAh} \mathrm{cm}^{-2}$ was measured and this value stabilized to $5.5 \mathrm{mAh} \mathrm{cm}^{-2}$ after 10 cycles when the mass content was $7.3 \mathrm{mg} \mathrm{cm}^{-2}$. For sulfur content as high as $9.1 \mathrm{mg} \mathrm{cm}^{-2}$, the initial areal capacity of the S@BPCS cathode was $8 \mathrm{mAh} \mathrm{cm}^{-2}$, stabilizing at $6.6 \mathrm{mAh} \mathrm{cm}^{-2}$ after 10 cycles. It is noteworthy that the current density is calculated to be as high as $9.7 \mathrm{~mA} \mathrm{~cm}-2$. Figure $4 \mathrm{~g}$ summarizes the areal capacities of different sulfur-loaded batteries. The electrode masses of 7.3 and $9.1 \mathrm{mg} \mathrm{cm}^{-2}$ used in this study are much higher than those of previously reported $\mathrm{Na}-\mathrm{S}$ batteries (Supplementary Fig. 22) and commercial LIBs $\left(4.0 \mathrm{mg} \mathrm{cm}^{-2}\right)$. To illustrate the importance of this work, we compared the capacity and rate capabilities of the $\mathrm{Na}-\mathrm{S}$ batteries in Fig. $4 \mathrm{~h}$.

Mechanisms of reversible reactions in the Na-S battery. To investigate the electrochemical reactions and corresponding mechanisms, in situ XRD, in situ Raman, ex situ HRTEM/SAED, DFT calculations, and ex situ XPS analysis were performed. The in situ Raman spectrum which represents a vibration band for sulfur at $475 \mathrm{~cm}^{-125}$, at a potential of $2.8 \mathrm{~V}$, which is supported by the in situ XRD pattern. In Fig. 5j, the XRD pattern has a diffraction peak at $23.08^{\circ}$, which is indexed to the (240) plane of sulfur (JCPDF\# 08-0247). The intensity of the sulfur vibrational band was reduced and a new vibrational band appears at $451 \mathrm{~cm}^{-1}$ at a potential of $2.25 \mathrm{~V}$, which is attributed to longchain Na-polysulfides $\left(\mathrm{Na}_{2} \mathrm{~S}_{8}\right)$. This result was supported by in situ XRD, where the diffraction peak appearing at $22.95^{\circ}$ is due to the formation of Na-polysulfides by the reduction of sulfur. After the long-chain Na-polysulfides reduced to short-chain polysulfides on further discharge, the reduction mechanism was studied. Figure $5 \mathrm{a}, \mathrm{b}$ shows HRTEM/SAED images, which confirm the reduction of sulfur to Na-polysulfides $\left(\mathrm{Na}_{2} \mathrm{~S}_{5}\right)$ at a potential of $2 \mathrm{~V}$. This is consistent with the XRD diffraction peak at $12.198^{\circ}$ of $\mathrm{Na}_{2} \mathrm{~S}_{5}$ (JCPDF\# 27-0792) corresponding to the (020) plane and the Raman vibrational bands at 474 and $451 \mathrm{~cm}^{-1}$ 

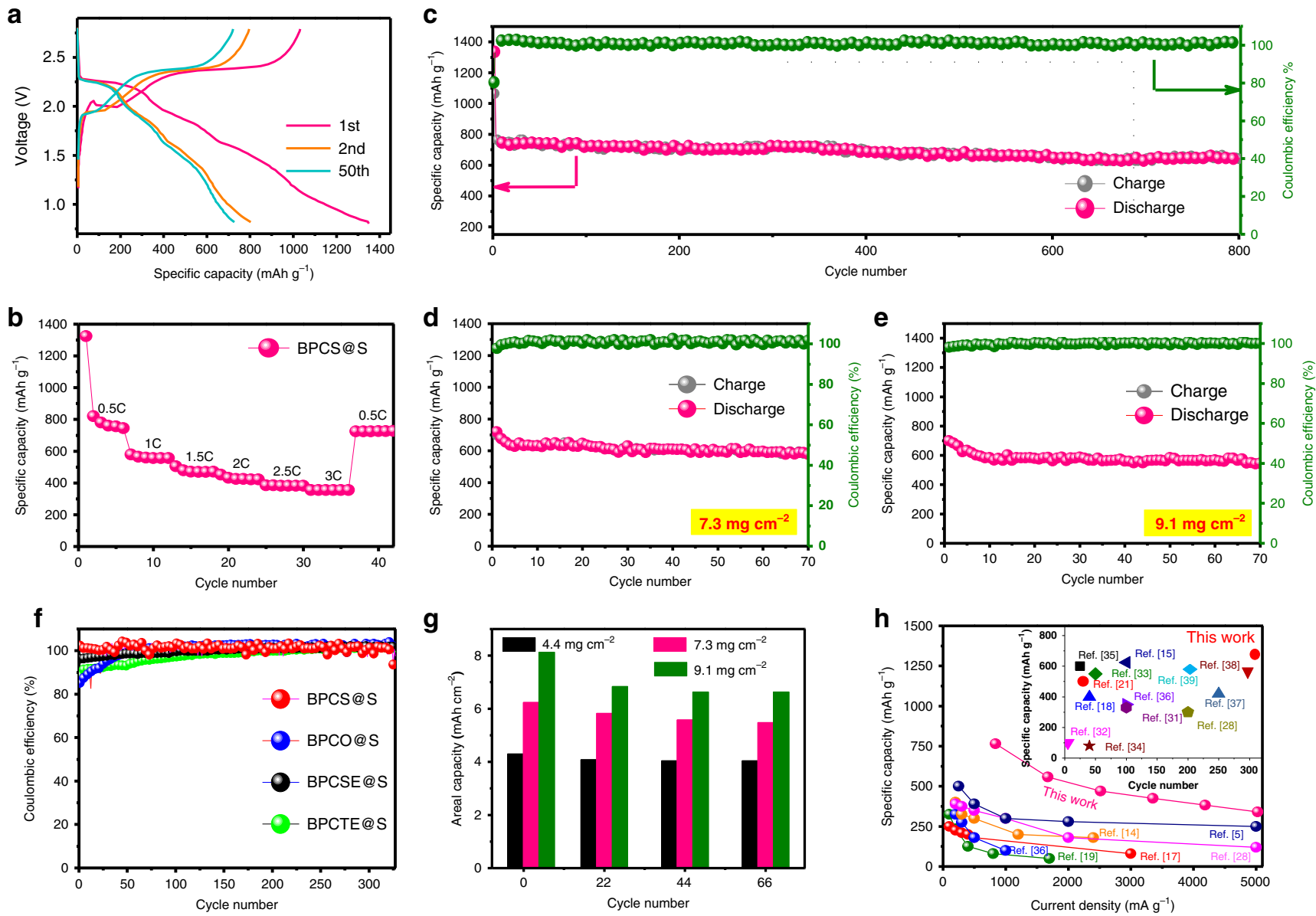

Fig. 4 Electrochemical performance of the bipyramid prism S@BPCS electrode. a Charge-discharge profiles at different cycle numbers. b Rate capabilities at different current densities. c Rate performance and the corresponding Coulombic efficiency at $0.5 \mathrm{C}$. d Rate performance and the corresponding Coulombic efficiency with mass loading $7.3 \mathrm{mg} \mathrm{cm}^{-2}$. e Rate performance with mass loading $9.1 \mathrm{mg} \mathrm{cm}^{-2}$. $\mathbf{f}$ Coulombic efficiency of different metal chalcogenides. $\mathbf{g}$ Areal capacities of all electrodes with different mass loadings at different cycle numbers and $\mathbf{h}$ comparison of the rate performance and capacity of previously reported $\mathrm{Na}-\mathrm{S}$ batteries with this work.

attributed to $\mathrm{Na}_{2} \mathrm{~S}_{5}$. On further discharge at $1.65 \mathrm{~V}$, the longchain polysulfides successfully reduced to short-chain polysulfides $\left(\mathrm{Na}_{2} \mathrm{~S}_{4}\right)$ and the corresponding

XRD pattern shows a diffraction peak at $19.93^{\circ}$ indexed to the (112) plane that was strongly attributed to $\mathrm{Na}_{2} \mathrm{~S}_{4}$ (JCPDF\# 251112 ) and it was robustly confirmed with HRTEM/SAED (Fig. 5c, d) and a Raman vibrational band at $472 \mathrm{~cm}^{-125}$. Furthermore, for discharge at $1.2 \mathrm{~V}$, a new XRD diffraction peak was generated at $11.84^{\circ}$ which is indexed to the (101) plane of $\mathrm{Na}_{2} \mathrm{~S}_{2}$ (JCPDF\#811764) and was subsequently confirmed with HRTEM/SAED (Fig. 5e, f) and a Raman vibrational band at $474 \mathrm{~cm}^{-1}$ for $\mathrm{Na}_{2} \mathrm{~S}_{2}{ }^{25}$. Subsequently, when the cell was deeply discharged at 0.8 $\mathrm{V}$, a new peak at $16.5^{\circ}$ was generated which indexed to the (122) plane of JCPDF\#47-0178 and is ascribed to $\mathrm{Na}_{2} \mathrm{~S}^{41}$. Figure $5 \mathrm{i}$ shows the CV curve labeled with polysulfide formed at different voltage during discharge process. Figure $5 \mathrm{~g}$, h showing HRTEM/ SAED and a Raman vibrational band (Fig. $6 \mathrm{~b}$ ) at $473 \mathrm{~cm}^{-1}$ which is attributed to $\mathrm{Na}_{2} \mathrm{~S}$, supporting the XRD result. The first discharge process could, therefore, be labeled with corresponding polysulfides as described in Fig. 6a, and the entire reduction process can be written as follows:

$$
\mathrm{S} \rightarrow \mathrm{Na}_{2} \mathrm{~S}_{\mathrm{X}} \rightarrow \mathrm{Na}_{2} \mathrm{~S}_{6,5} \rightarrow \mathrm{Na}_{2} \mathrm{~S}_{4,3} \rightarrow \mathrm{Na}_{2} \mathrm{~S}_{2} \rightarrow \mathrm{Na}_{2} \mathrm{~S}
$$

When the cell was charged to $2.8 \mathrm{~V}, \mathrm{Na}_{2} \mathrm{~S}$ and $\mathrm{Na}_{2} \mathrm{~S}_{5}$ are not detected in the XRD pattern. This means that the conversion rate of short-chain polysulfides to long-chain polysulfides is fast, and that could be a reason why $\mathrm{Na}_{2} \mathrm{~S}$ and $\mathrm{Na}_{2} \mathrm{~S}_{5}$ are not detected with in situ XRD. In addition, the intensity of the XRD peaks decreases, which indicates a fast transformation of $S$ to long-chain $\mathrm{Na}$-polysulfides and to $\mathrm{Na}_{2} \mathrm{~S}$. This study elucidates the reduction reactions of $\mathrm{S}$ to $\mathrm{Na}_{2} \mathrm{~S}$ and presents a new mechanism to explore the significance of polar and catalytic BPCS. The polar and catalytic BPCS diminishes the dissolution of polysulfides, facilitates the fast transformation of long-chain polysulfides to $\mathrm{Na}_{2} \mathrm{~S}$, alleviates the shuttle effect, and delivers excellent electrochemical performance. Furthermore, to check for dissolution of polysulfides in the electrolyte, the fiberglass disk that was used as a separator was removed from the cell after cycling for ex situ XPS of S. Figure $6 c\left(c_{1}-c_{3}\right)$ shows high-resolution XPS spectra of S for the S@BPCTE, S@BPCSE, and S@BPCS batteries separators, respectively. The peaks in the range of binding energies of $160-165 \mathrm{eV}$ are due to dissolved polysulfides ${ }^{27}$ and the peaks in the range of $165-170 \mathrm{eV}$ are due to the formation of $\mathrm{SO}_{X}$. Figure $6 c\left(c_{3}\right)$ shows that there are no Na-polysulfide peaks in S@BPCS separator and the rest have dissolved polysulfide peaks. These findings clearly demonstrate that the polar and catalytic BPCS can efficiently capture the Na-polysulfides.

Lastly, the visible difference in the adsorption of polysulfides in the BPCS was performed using a $\mathrm{Na}_{2} \mathrm{~S}_{6}$ solution. Figure $6 \mathrm{~d}$ clearly shows that when carbon was added to the $\mathrm{Na}_{2} \mathrm{~S}_{6}$ solution, there was no change in the yellow color of polysulfides whereas, when BPCS was added to $\mathrm{Na}_{2} \mathrm{~S}_{6}$ solution, the yellowish color turns 


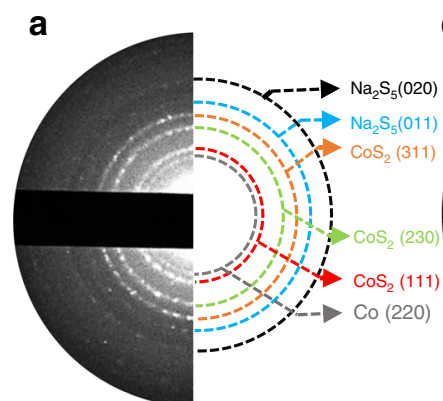

$2 \mathrm{~V}$

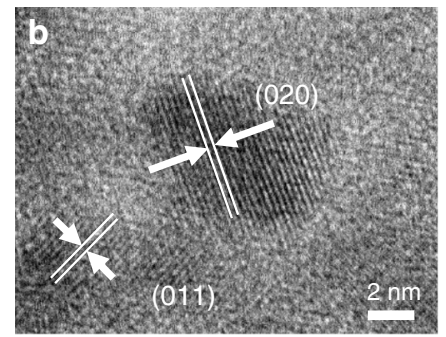

C

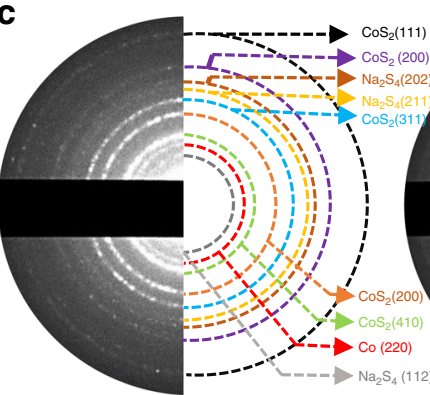

$1.65 \mathrm{~V}$

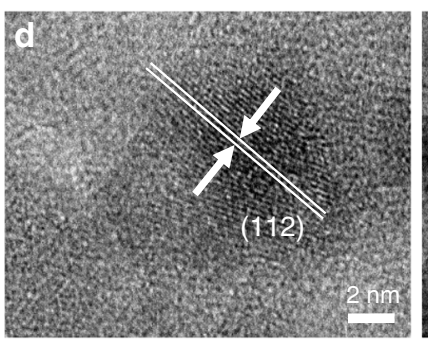

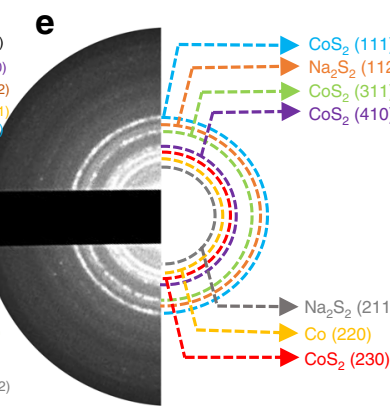

$1.2 \mathrm{~V}$

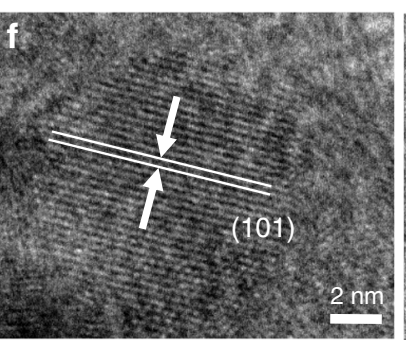

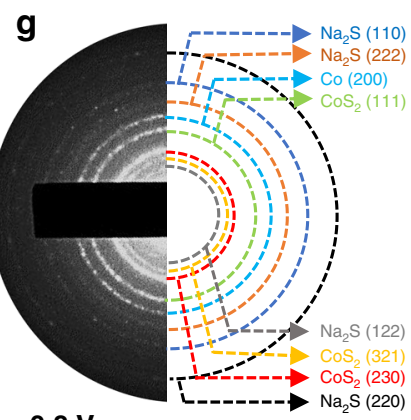

$0.8 \mathrm{~V}$

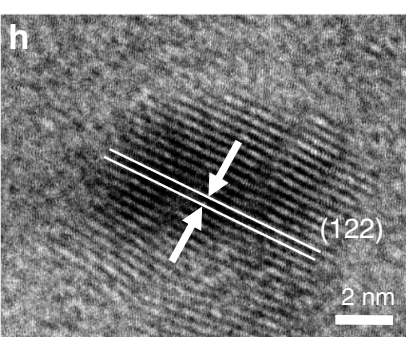

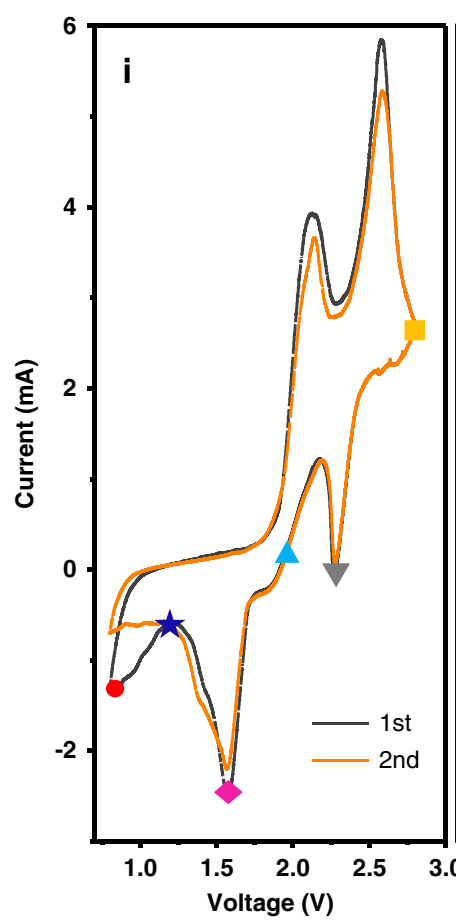

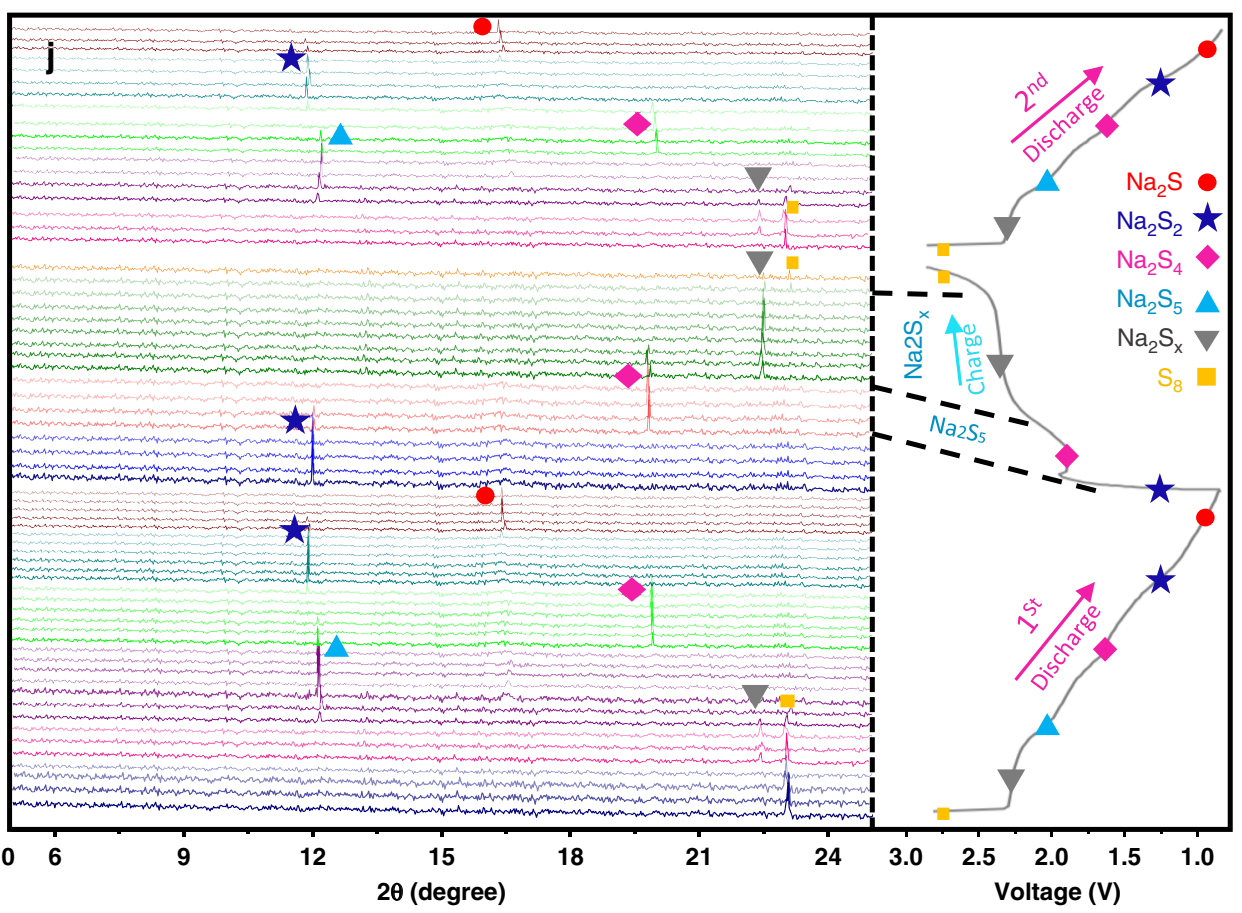

Fig. 5 HRTEM images and SAED patterns of S@BPCS electrode at different discharge voltages. a SAED pattern and $\mathbf{b}$ corresponding HRTEM at 2 V. c SAED pattern and $\mathbf{d}$ corresponding HRTEM at $1.65 \mathrm{~V}$; e SAED pattern and $\mathbf{f}$ corresponding HRTEM at $1.2 \mathrm{~V}$ and $\mathbf{g}$ SAED pattern and $\mathbf{h}$ corresponding HRTEM at $0.8 \mathrm{~V}$; mechanistic characterization of the S@BPCS electrode. $\mathbf{i}$ Cyclic voltammogram. $\mathbf{j}$ In situ X-rays diffraction (XRD) patters in the selected range of degree 2-theta (right) with first two charge-discharge profiles at a current density of $0.5 \mathrm{C}$.

colorless after few hours demonstrating the strong interaction and adsorption capability of polar BPCS towards NaPSs. The S@BPCS composite has internal void space of about $376 \mathrm{~nm}$, which is enough to provide adequate space for NaPSs and tolerate the strain during sodiation and desodiation as shown in Fig. 6e.

Computational results. DFT calculations were performed with the SCAN + rvv10 functional to understand the interactions of NaPSs with $\mathrm{CoX}_{2}$ cathode hosts. The lattice parameters of the structures optimized with SCAN + rvv10 are in excellent agreement with experimental results, as shown in Supplementary Fig. 23 and Supplementary Table 1. As can be seen from the density of states plots in Supplementary Fig. 24, there are states at the Fermi level in the spin up-channel for all structures resulting in half-metallic behavior. The binding of polysulfides to the surface of $\mathrm{CoX}_{2}$ materials were further investigated with slab calculations. The energies of different surface terminations of pyrite $\left(\mathrm{p}-\mathrm{CoS}_{2}\right)$ and marcasite $\left(\mathrm{m}-\mathrm{CoTe}_{2}, \mathrm{~m}-\mathrm{CoSe}_{2}\right) \mathrm{CoX}_{2}$ structures are shown in Supplementary Table 2. The surface energies $(\gamma)$ were calculated using Eq. (1)

$$
\gamma=\frac{E_{\text {slab }}-N^{*} E_{\text {bulk }}}{2 A}
$$

where $E_{\text {slab }}$ is the slab energy for a given surface (single point or relaxed surface), $E_{\text {bulk }}$ is the energy of relaxed bulk geometry per formula unit, $N$ is the number of formula units in the slab, and $A$ 

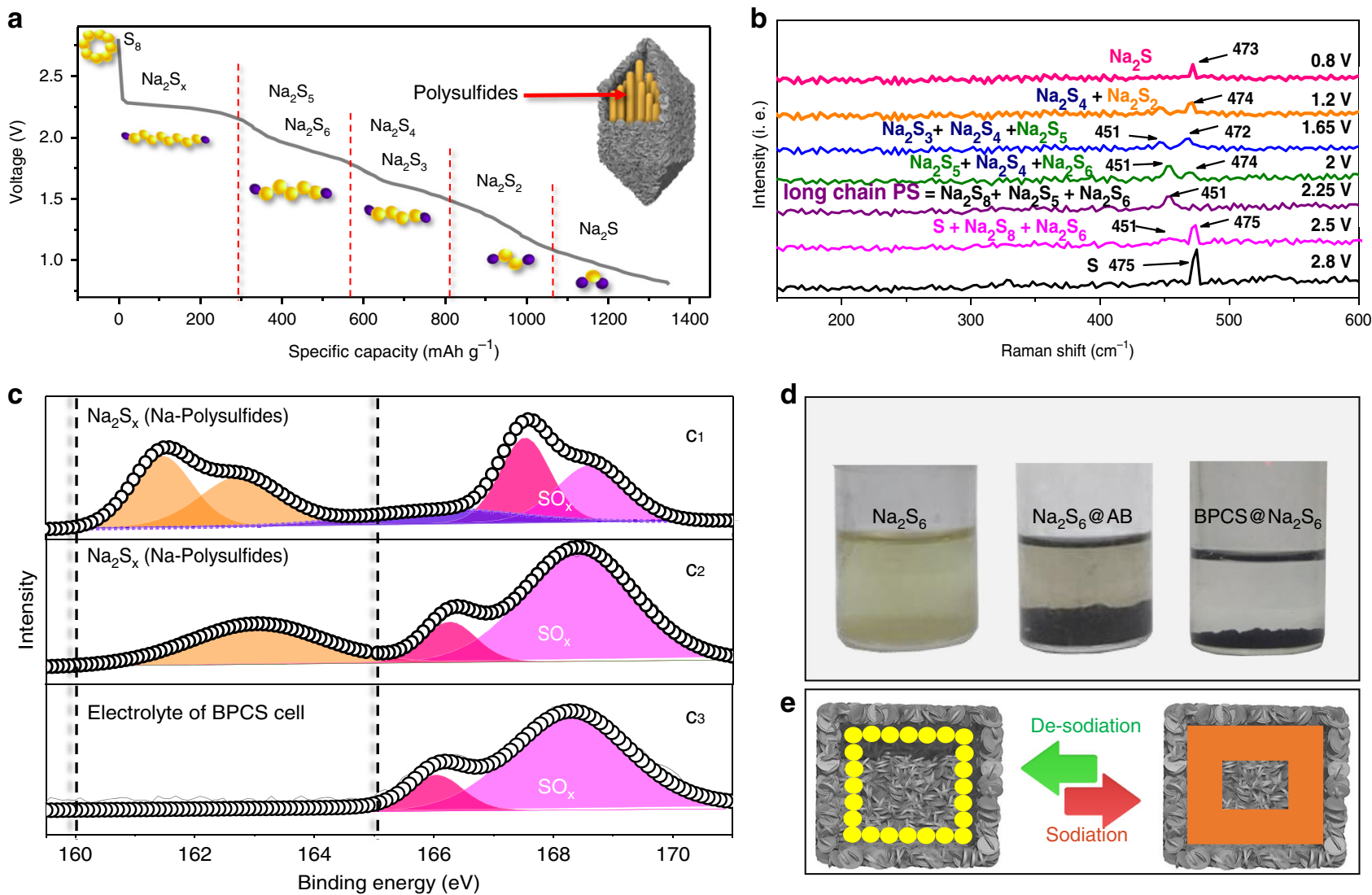

Fig. 6 Mechanistic illustration of formation and adsorption of polysulfides. a Initial discharge of the S@BPCS composite labeled with practically interpreted polysulfides at different potentials. b In situ Raman spectra of the S@BPCS cell at different potentials. c XPS spectra of the S 2p of S@BPCS cell electrolyte after cycling. $\mathbf{d}$ Visual display of adsorption of $\mathrm{Na}_{2} \mathrm{~S}_{6}$ by BPCS and $\mathbf{e}$ scheme presenting the volume change during sodiation and desodiation.

is the area of the surface. To screen a wider range of possible surfaces for different $\mathrm{CoX}_{2}$ structures, the cheaper PBEsol functional was used instead of the SCAN + rvv10 functional. Supplementary Table 2 shows the surface energy of the eight-lowest energy surfaces of $\mathrm{p}-\mathrm{CoS}_{2}$ and the ten lowest energy surfaces of $\mathrm{m}-\mathrm{CoSe}_{2}$ and $\mathrm{m}-\mathrm{CoTe}_{2}$. As can be seen from Supplementary Table 2, the lowest energy surface for $\mathrm{p}-\mathrm{CoS}_{2}$ is (100), followed by the (210) surface, which is consistent with previous XRD and TEM results ${ }^{28,29}$. Several low energy surfaces are present in the $\mathrm{m}-\mathrm{CoSe}_{2}$ and $\mathrm{m}-\mathrm{CoTe} \mathrm{e}_{2}$ marcasite structures, including the (010), (101), and (211) surfaces, which is consistent with low energy surfaces observed computationally and experimentally for analogous marcasite surfaces ${ }^{30,42}$. The (100) surface of $\mathrm{p}-\mathrm{CoS}_{2}$ and the (101) and (010) surfaces of $\mathrm{m}-\mathrm{CoSe}_{2}$ and $\mathrm{m}-\mathrm{CoTe} \mathrm{T}_{2}$ were chosen to study the binding of polysulfides. The geometries of all of the low energy slabs predicted with PBEsol were reoptimized with SCAN + rvv10 before further binding calculations.

In order to understand the nature of binding between NaPSs and the cathode hosts, the enthalpy of $\mathrm{Na}_{2} \mathrm{~S}_{y}$ polysulfide molecules of different chain lengths $(y=1,2,4,5$, and 6) bound to both the $\mathrm{p}-\mathrm{CoS}_{2}(100)$ surface and a graphene sheet were calculated. The formation energy of the NaPSs molecules was taken as the difference in the energy between a slab of the cathode host with $\left(E_{\text {slab }+ \text { Naxs }}\right)$ and without the NaPSs $\left(E_{\text {slab }}\right)$, referenced to the solid $\mathrm{S}$ and $\mathrm{Na}_{2} \mathrm{~S}$ phases via $E_{\text {form }}=E_{\text {slab }+\mathrm{NaxS}}-E_{\text {slab }}-x / 2 \times$ $E_{\mathrm{Na} 2 \mathrm{~S}}-(1-x / 2) \times E_{\mathrm{s}}$. The effects of solvation on the slabs with and without the bound NaPSs were taken into account via the inclusion of an implicit solvation model in VASPsol ${ }^{43}$. The lowest energy binding geometries for each NaPS are shown in (Supplementary Fig. 25). The formation energies $\left(E_{\text {form }}\right)$ of solid phases of $\mathrm{Na}_{2} \mathrm{~S}, \mathrm{Na}_{2} \mathrm{~S}_{2}, \mathrm{Na}_{2} \mathrm{~S}_{4}, \mathrm{Na}_{2} \mathrm{~S}_{5}, \mathrm{Na}_{2} \mathrm{~S}_{6}$, and $\mathrm{S}$ were calculated

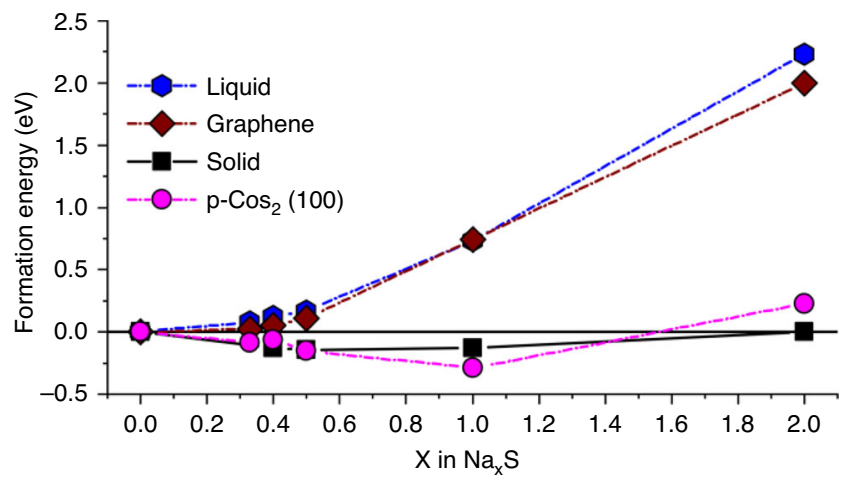

Fig. 7 Convex energy hull of $\mathrm{Na}_{2} \mathrm{~S}_{y}$ phases per mol of $\mathrm{S}(x=2 / y)$ from DFT calculations. Energy of solid $\mathrm{Na}_{2} \mathrm{~S}_{y}$ structures is shown with black symbols relative to end-member compositions of solid $\mathrm{Na}_{2} \mathrm{~S}$ and $\mathrm{S}$. The energies of molecular $\mathrm{Na}_{2} \mathrm{~S}_{y}$ geometries bound to the $\mathrm{p}-\mathrm{CoS}_{2}(100)$ surface (magenta), graphene surface (brown) and in the free liquid state (blue) with implicit solvation are shown with dashed lines.

using the SCAN + rvv10 functional as shown in Fig. 7 (black symbols). The formation energies of intermediate $\mathrm{Na}_{2} \mathrm{~S}_{y}$ phases $\left(E_{\mathrm{NaxS}}\right)$ normalised to one mol of $\mathrm{S}(x=2 / y)$ are reported relative to the end member configurations of $\mathrm{Na}_{2} \mathrm{~S}\left(E_{\mathrm{Na} 2 \mathrm{~S}}\right)$ and $\mathrm{S}\left(E_{\mathrm{s}}\right)$ by the formula $E_{\mathrm{form}}=\mathrm{E}_{\mathrm{Na} x \mathrm{~S}}-x / 2 \times E_{\mathrm{Na} 2 \mathrm{~S}}-(1-x / 2) \times E_{\mathrm{s}}$. With respect to $\mathrm{Na}$ metal, the sequence of reactions from $\mathrm{S} \rightarrow \mathrm{Na}_{2} \mathrm{~S}_{5}$ $\rightarrow \mathrm{Na}_{2} \mathrm{~S}_{4} \rightarrow \mathrm{Na}_{2} \mathrm{~S}_{2} \rightarrow \mathrm{Na}_{2} \mathrm{~S}$ are predicted to occur at voltages of $2.28 \mathrm{~V} \rightarrow 2.08 \mathrm{~V} \rightarrow 1.91 \mathrm{~V} \rightarrow 1.82 \mathrm{~V}$, which are in good agreement with previous computational studies ${ }^{44}$ and the experimental cycling data in Fig. 6a, particularly for the reactions 
from $\mathrm{S}$ to $\mathrm{Na}_{2} \mathrm{~S}_{4}$, where a significant overpotential does not occur. The formation energy of the free $\mathrm{Na}_{2} \mathrm{~S}_{y}$ molecules in the presence of the implicit solvent, but without the presence of the catalyst host, is also shown in Fig. 7 to approximate the energy of the "liquid" state. From Fig. 7, it can be seen that the formation energy of the NaPSs bound to the graphene cathode host is very similar to the free NaPSs in the "liquid", indicating a very weak binding between the nonpolar graphene surface and the NaPSs as observed in previous studies ${ }^{45}$.

In comparison, the formation energy of all NaPSs bound to the $\mathrm{p}-\mathrm{CoS}_{2}$ (100) surface are lowered significantly, primarily due to the strong interaction between the $\mathrm{Na}_{2} \mathrm{~S}_{y}$ molecules and the polar $\mathrm{p}-\mathrm{CoS}_{2}$ surface. The difference in the energy between the NaPSs bound to the $\mathrm{p}-\mathrm{CoS}_{2}$ (100) surface and the 'liquid state' increases systematically as the chain length, $y$, decreases ( $x$ increases), reaching $2 \mathrm{eV}$ for the $\mathrm{Na}_{2} \mathrm{~S}$ molecule. As discussed further in Supplementary Fig. 26a, the strong binding of the NaPSs to the surface is related to charge transfer between the undercoordinated $\mathrm{Co}^{2+}$ sites on the surface to the $\mathrm{S}$ atoms in the $\mathrm{Na}_{2} \mathrm{~S}_{y}$ cluster.

Interestingly, after binding to the $\mathrm{p}-\mathrm{CoS}_{2}$ (100) surface, the enthalpy of the bound $\mathrm{Na}_{2} \mathrm{~S}_{y}$ molecules closely matches the energy of the solid $\mathrm{Na}_{2} \mathrm{~S}_{y}$ phases. An absolute comparison of the energies is not possible from Fig. 7 as entropic contributions and the presence of explicit solvation have not been included, however, this close matching between the energy of the molecular NaPSs and solid $\mathrm{Na}_{2} \mathrm{~S}_{y}$ phases is likely to be beneficial, in which reactions in the molecular state are expected to be facile. For example, if the binding of a $\mathrm{Na}_{2} \mathrm{~S}$ molecule to the cathode host is weak, as in the graphene case, the voltage required to drive the reaction $\mathrm{Na}_{2} \mathrm{~S}_{2}+$ $2 \mathrm{Na}^{+}+2 \mathrm{e}^{-} \rightarrow 2 \mathrm{Na}_{2} \mathrm{~S}$ on the graphene at is $0.59 \mathrm{~V}$. As the voltage for the solid-solid reaction of $\mathrm{Na}_{2} \mathrm{~S}_{2}$ to $\mathrm{Na}_{2} \mathrm{~S}$ is $1.82 \mathrm{~V}$, a large overpotential of $1.23 \mathrm{~V}$ would be required to facilitate the reaction in the molecular state. If the cathode host binds the NaPSs too strongly, then the energy of the anchored $\mathrm{Na}_{2} \mathrm{~S}$ molecule will be lower than the $\mathrm{Na}_{2} \mathrm{~S}$ solid. $\mathrm{Na}_{2} \mathrm{~S}$ molecules will therefore cover the cathode host surface instead of forming bulk $\mathrm{Na}_{2} \mathrm{~S}$ particles, reducing the ability for it to catalyze further reactions. By balancing the energy between the anchored and bulk $\mathrm{Na}_{2} \mathrm{~S}_{y}$ materials, facile molecular reactions can take place on the cathode host surface which lead to the formation of bulk $\mathrm{Na}_{2} \mathrm{~S}$ particles.

The formation energy of $\mathrm{Na}_{2} \mathrm{~S}_{\mathrm{y}}$ molecules bound to the marcasite $\mathrm{p}-\mathrm{CoSe}_{2}$ (100), m-CoSe $(010), \mathrm{m}-\mathrm{CoSe}_{2}$ (101), and $\mathrm{m}-\mathrm{CoTe}_{2}(010)$ surfaces were also calculated, as shown in Supplementary Fig. 27. It can be seen from Supplementary Fig. 27 that all of the $\mathrm{CoX}_{2}$ hosts strongly bind the NaPS molecules, resulting in formation energies that are close to those of the solid $\mathrm{Na}_{2} \mathrm{~S}_{y}$ phases. For the $\mathrm{Na}_{2} \mathrm{~S}$ end member, a small difference in the formation energy is observed on analogous surfaces of materials with the same structure, but with a different anion, i.e., $\mathrm{p}-\mathrm{CoS}_{2}(100)$ vs. $\mathrm{p}-\mathrm{CoSe}_{2}(100)$ and $\mathrm{m}$ $\mathrm{CoSe}_{2}(010)$ vs. $\mathrm{m}-\mathrm{CoTe}_{2}(010)$. The difference in the formation energy of a $\mathrm{Na}_{2} \mathrm{~S}$ molecule is larger on different surfaces of the same structure, e.g., $\mathrm{m}-\mathrm{CoSe}_{2}(101)$ vs. $\mathrm{m}-\mathrm{CoSe}_{2}(010)$, suggesting that structural differences in these materials (pyrite vs marcasite) may play a more important role in this family of materials than the nature of the anion (i.e., $\mathrm{S}, \mathrm{Se}$, and Te). This result is in line with the experimental electrochemical results in Fig. S20, where the marcasite based BPCSE and BPCTE structures have similar rate performance, whereas the pyrite based BPCS structure has markedly better rate performance.

\section{Discussion}

Hollow polar and catalytic bipyramid prism $\mathrm{CoS}_{2} / \mathrm{C}$ (BPCS) have been designed as an efficient sulfur host for $\mathrm{Na}-\mathrm{S}$ batteries. BPCS have a unique architecture with a hierarchical surface and wide internal spaces that provide sufficient room to accommodate sodium polysulfides (NaPSs) and can withstand volume expansion during sodiation and desodiation. This study provides a systematic method for further understanding of the reversible reaction mechanism during the charge/discharge process. In/ ex situ experimental results elucidate the discharge mechanism and confirm the importance of polar and catalytic BPCS in accelerating the electrochemical reaction and enabling the direct conversion of short-chain polysulfides to long-chain polysulfides (instead of $\mathrm{Na}_{2} \mathrm{~S}_{5}$ ) without affecting the reactants or products, thereby reducing the one-step reaction process and accelerating the reaction kinetics. Furthermore, DFT calculations support the mechanism that polysulfide adsorption is superior for metal sulfides, selenides and tellurides with interwoven surfaces and chemical composition when compared to carbon hosts. This study shows that a polar and catalytic sulfur host with unique architecture can catalyze the polysulfides conversion reactions and suppress the shuttle effect by chemisorption, resulting in good electrochemical performance. While the focus of this study was on cobalt based catalytic sulfur hosts, the combined experimental and computational methodology used in this work is widely applicable to other transition metal dichalcogenide systems.

\section{Methods}

Synthesis of metal chalcogenides host and their sulfur composites. Synthesis of Co-bipyramid prisms: Typically, $1.0 \mathrm{~g}$ of polyvinylpyrrolidone (PVP) and $0.135 \mathrm{~g}$ of cobalt acetate tetrahydrate were dissolved in $500 \mathrm{ml}$ of ethanol at room temperature under sonication to form a clear solution. The solution was then heated to $90^{\circ} \mathrm{C}$ under reflux conditions for $1.5 \mathrm{~h}$. Afterward, the precipitates were collected via centrifugation at $2795 \times g$, rinsed thoroughly with hot ethanol and water (preheated at $60^{\circ} \mathrm{C}$ ) for at least 15 times to remove the attached PVP on the surface before being fully dried in air (Fig. 1a).

Synthesis of Co/C hollow bipyramid prisms: To synthesize hollow bipyramid prisms, the co-precursor was calcined at $500^{\circ} \mathrm{C}$ for $3 \mathrm{~h}$ with the ramp rate of $5^{\circ} \mathrm{C}$ $\min ^{-1}$ under Ar and $\mathrm{H}_{2}$ mixed atmosphere.

Synthesis of hollow $\mathrm{Co}_{3} \mathrm{O}_{4} / \mathrm{C}$ bipyramid prisms with the hierarchical surface (BPCO): To synthesize hollow BPCO the above $\mathrm{Co} / \mathrm{C}$ was calcined at $550^{\circ} \mathrm{C}$ for $2 \mathrm{~h}$ with the ramp rate of $3^{\circ} \mathrm{C} \mathrm{min}-1$ under an air atmosphere.

Synthesis of $\mathrm{CoSe}_{2} / \mathrm{C}$ bipyramid prisms with the hierarchical surface (BPCSE): To synthesize BPCSE, the BPCO was calcined with Se powder putting in separate boats according to up and low stream at $300^{\circ} \mathrm{C}$ for $3 \mathrm{~h}$ with the ramp rate of $2{ }^{\circ} \mathrm{C}$ $\min ^{-1}$ under Ar atmosphere.

Synthesis of $\mathrm{CoS}_{2} / C$ bipyramid prisms with the hierarchical surface (BPCS): To synthesize BPCS, the BPCO was refluxed with thioacetamide (TAA) for $12 \mathrm{~min}$ at $90^{\circ} \mathrm{C}$ and precipitates were collected with centrifuge machine, after drying, the powder was heated at $350^{\circ} \mathrm{C}$ for $2 \mathrm{~h}$ with the ramp rate of $2{ }^{\circ} \mathrm{C} \mathrm{min}-1$ under $\mathrm{Ar}$ atmosphere.

Synthesis of $\mathrm{CoTe}_{2} / C$ bipyramid prisms with hierarchical surface (BPCTE): To synthesize BPCTE, the BPCO was heated with Te powder, putting it at low stream in separate boats and Te powder at upstream at $700{ }^{\circ} \mathrm{C}$ for $3 \mathrm{~h}$ with the ramp rate of $3{ }^{\circ} \mathrm{C}$ min $^{-1}$ under $\mathrm{Ar}$ atmosphere.

Synthesis of S@BPCS: For the synthesis of sulfur cathode, the sulfur host and sublimed sulfur were well mixed in mortar with the weight ratio of 1:4 and then transferred to a heating boat covered with $\mathrm{Al}$-foil and heated at $155^{\circ} \mathrm{C}$ in a tube furnace for $12 \mathrm{~h}$ with a ramp rate of $2^{\circ} \mathrm{C} \min ^{-1}$ under an $\mathrm{Ar}$ atmosphere. Additionally, the sulfur composite was heated at $190^{\circ} \mathrm{C}$ for $30 \mathrm{~min}$. to remove the excessive sulfur from the surface. Sulfur composites of all other metal chalcogenides were also prepared by the similar method.

Synthesis of $\mathrm{Na}_{2} \mathrm{~S}_{6}$ solution: For the synthesis of $\mathrm{Na}_{2} \mathrm{~S}_{6}, \mathrm{Na}_{2} \mathrm{~S}$ and $\mathrm{S}$ were stirred in tetraethylene glycol dimethyl ether at $80^{\circ} \mathrm{C}$ for $12 \mathrm{~h}$. The dark yellowish black colour $\mathrm{Na}_{2} \mathrm{~S}_{6}$ solution was obtained with $0.067 \mathrm{M}$ concentration, which was further diluted before the absorption test.

Materials characterization. The morphological investigations were done by FESEM (JSM-7800F, Japan), SEM (JSM-6510LV) and TEM (JEM-2100, Japan) The elemental composition was measured by EDS using EDS, JEOL-6300F. Phase purity and chemical compositions of all the samples were investigated by XRD (MAXima-X XRD-7000) in the range of $5-90^{\circ}$ at a scan rate of $5^{\circ} \mathrm{min}^{-1}$ and by XPS was using a Thermo Scientific ESCALAB 250Xi electron spectrometer. TGA was performed to measure the sulfur contents in the host using an SDTQ600 analyzer (TA instrument) in the Ar atmosphere at $600{ }^{\circ} \mathrm{C}$ with a heating rate of $10^{\circ} \mathrm{C} \mathrm{min}^{-1}$. The textural properties (pore size and surface area) were investigated by nitrogen adsorption-desorption using BET (Quantachrome Instruments, USA). 
In situ characterization. The in situ Raman spectra were collected using Lab-RAM HR Evolution (Horiba) Raman microscope (EL-CELL Germany), with excitation wavelengths laser of $532 \mathrm{~nm}$ under discharged/charged at a sweep rate of $1 \mathrm{mV} \mathrm{s}^{-1}$ using CHI workstation (CHI 660D). For in situ XRD, the preparation method of half-cell was similar, $4 \mathrm{~mm}$ hole was punched on the steel caps and steel spacer on both the anode and cathode sides and the holes were completely sealed with Kapton film and an $\mathrm{AB}$ glue coating. To enhance the intensity of XRD peaks, a thicker layer of cathode material was deposited $\left(7 \mathrm{mg} \mathrm{cm}^{-2}\right)$ on an aluminum substrate. The discharge/charge was performed on a LAND workstation (Wuhan, China) at a current density of $500 \mathrm{~mA} \mathrm{~g}^{-1}$.

Ex situ characterization. The ex situ HRTEM and SAED patterns were obtained at different stages of discharge. Firstly, batteries were discharged up to the required potential using a LAND workstation and at the end of discharge, the batteries were opened in a glove box to collect sample material. Afterward, the samples were further used for TEM measurements. For ex situ XPS, the batteries were discharged up to the mentioned potential and after batteries were opened in the glove box and collected sample used for XPS analysis. The ex situ XPS of battery electrolyte was also performed after full discharge at $0.8 \mathrm{~V}$.

Electrochemical measurements. The electrochemical measurements were performed using CR2032 coin-type cells. Films of the active materials were formed from a slurry of active material (cathode material), acetylene black (AB) carbon and polyvinylidene difluoride, mixed in the ratio of 8:1:1 in N-methyl-2pyrrolidone solvent. After mixing, the slurry was spread on a circular disk of aluminum with a doctor blade and dried at $60^{\circ} \mathrm{C}$ for $12 \mathrm{~h}$. CR2032 coin cells were assembled in an Ar filled glove box, pure sodium foil was used as a counter and a reference electrode and a Whatmann glass fiber disk was used as a separator with $1 \mathrm{M} \mathrm{NaClO}_{4}$ in tetraethylene glycol dimethyl ether as an electrolyte. The separator was used after drying at $120^{\circ} \mathrm{C}$ for $12 \mathrm{~h}$. The long cycle performance and rate capabilities were performed on LAND (Wuhan, China) electrochemical workstation in the potential window of $0.8-2.8 \mathrm{~V}$ and $\mathrm{CV}$ was performed at Arbin electrochemical workstation at a scan rate of $0.1 \mathrm{mV} \mathrm{s}^{-1}$.

DFT calculations. DFT calculations were performed to understand the interactions of NaPSs with $\mathrm{CoX}_{2}$ cathode hosts. Spin-unrestricted DFT calculations were performed in the VASP code using projector augmented wave pseudopotentials ${ }^{46,47}$. The SCAN meta-GGA functional has been shown to give accurate structures and energetics for a range of diversely bonded solid and molecular systems ${ }^{48,49}$. In this study, we used the recently developed SCAN + rvv10 $0^{50,51}$ extension to the original SCAN functional, which provides an accurate description of short, intermediate and long-range van der Waals interactions which are known to play an important role in binding in transition metal sulfide materials ${ }^{45}$. Bulk phases of $\mathrm{CoS}_{2}$ and $\mathrm{CoTe}_{2}$ were modeled with the pyrite $(\mathrm{Pa}-3)$ and marcasite $(\mathrm{Pnnm})$ structures, respectively, and will subsequently be referred to as $\mathrm{p}-\mathrm{CoS}_{2}$ and $\mathrm{m}-\mathrm{CoTe}_{2}$. In this study, the $\mathrm{CoSe}_{2}$ bipyramidal host primarily adopted the marcasite structure (m$\mathrm{CoSe}_{2}$ ). However, previous studies have shown that the energies of the pyrite and marcasite structures of $\mathrm{CoSe}_{2}$ are similar and so both the pyrite ( $\mathrm{p}-\mathrm{CoSe}_{2}$ ) and m$\mathrm{CoSe}_{2}$ phases were considered in this study for comparison. Additional details of the DFT calculations are presented in Supplementary Note 1.

\section{Data availability}

The data that supports this work is available in this paper, including supporting information and response files.

Received: 19 April 2020; Accepted: 25 September 2020; Published online: 16 October 2020

\section{References}

1. Wang, H., Zhang, W., Liu, H. \& Guo, Z. A strategy for configuration of an integrated flexible sulfur cathode for high-performance lithium-sulfur batteries. Angew. Chem. Int. Ed. 55, 3992-3996 (2016).

2. Su, Y.-S. \& Manthiram, A. Lithium-sulphur batteries with a microporous carbon paper as a bifunctional interlayer. Nat. Commun. 3, 1166 (2012).

3. Bruce, P. G., Freunberger, S. A., Hardwick, L. J. \& Tarascon, J.-M. Li-O2 and Li-S batteries with high energy storage. Nat. Mater. 11, 19 (2011).

4. Ji, X., Lee, K. T. \& Nazar, L. F. A highly ordered nanostructured carbon-sulphur cathode for lithium-sulphur batteries. Nat. Mater. 8, 500 (2009).

5. Zhang, B.-W. et al. Atomic cobalt as an efficient electrocatalyst in sulfur cathodes for superior room-temperature sodium-sulfur batteries. Nat. Commun. 9, 4082 (2018)

6. Seh, Z. W., Sun, J., Sun, Y. \& Cui, Y. A highly reversible room-temperature sodium metal anode. ACS Cent. Sci. 1, 449-455 (2015).
7. Tian, H. et al. Theoretical investigation of $2 \mathrm{D}$ layered materials as protective films for lithium and sodium metal anodes. Adv. Energy Mater. 7, 1602528 (2017).

8. Sakabe, S. NAS Battery Fire Incident and Response (NGK Insulators, Ltd.: Tokyo, 2011).

9. Park, C.-W. et al. Discharge properties of all-solid sodium-sulfur battery using poly (ethylene oxide) electrolyte. J. Power Sources 165, 450-454 (2007).

10. Kim, J.-S. et al. The short-term cycling properties of $\mathrm{Na} / \mathrm{PVdF} / \mathrm{S}$ battery at ambient temperature. J. Solid State Electrochem. 12, 861-865 (2008).

11. Park, C.-W., Ahn, J.-H., Ryu, H.-S., Kim, K.-W. \& Ahn, H.-J. Roomtemperature solid-state sodium/sulfur battery. Electrochem. Solid-State Lett. 9, A123-A125 (2006).

12. Ryu, H. et al. Discharge reaction mechanism of room-temperature sodium-sulfur battery with tetra ethylene glycol dimethyl ether liquid electrolyte. J. Power Sources 196, 5186-5190 (2011).

13. Carter, R. et al. A sugar-derived room-temperature sodium sulfur battery with long term cycling stability. Nano Lett. 17, 1863-1869 (2017).

14. Qiang, Z. et al. Ultra-long cycle life, low-cost room temperature sodium-sulfur batteries enabled by highly doped $(\mathrm{N}, \mathrm{S})$ nanoporous carbons. Nano Energy 32 , 59-66 (2017).

15. Zhang, B.-W. et al. In situ grown s nanosheets on $\mathrm{Cu}$ foam: an ultrahigh electroactive cathode for room-temperature Na-S batteries. ACS Appl. Mater. Interfaces 9, 24446-24450 (2017).

16. Zhang, L. et al. Self-assembling hollow carbon nanobeads into double-shell microspheres as a hierarchical sulfur host for sustainable room-temperature sodium-sulfur batteries. ACS Appl. Mater. Interfaces 10, 20422-20428 (2018).

17. Hwang, T. H., Jung, D. S., Kim, J.-S., Kim, B. G. \& Choi, J. W. Onedimensional carbon-sulfur composite fibers for $\mathrm{Na}-\mathrm{S}$ rechargeable batteries operating at room temperature. Nano Lett. 13, 4532-4538 (2013).

18. Yu, X. \& Manthiram, A. Room-temperature sodium-sulfur batteries with liquid-phase sodium polysulfide catholytes and binder-free multiwall carbon nanotube fabric electrodes. J. Phy. Chem. C 118, 22952-22959 (2014).

19. Lu, Q. et al. Freestanding carbon fiber cloth/sulfur composites for flexible room temperature sodium-sulfur batteries. Energy Storage Mater. 8, 77-84 (2017).

20. Wang, X. et al. Structural and chemical synergistic encapsulation of polysulfides enables ultralong-life lithium-sulfur batteries. Energy Environ. Sci. 9, 2533-2538 (2016).

21. Wei Seh, Z. et al. Sulphur-TiO 2 yolk-shell nanoarchitecture with internal void space for long-cycle lithium-sulphur batteries. Nat. Commun. 4, 1331 (2013).

22. Jiang, J. et al. Encapsulation of sulfur with thin-layered nickel-based hydroxides for long-cyclic lithium-sulfur cells. Nat. Commun. 6, 8622 (2015).

23. Rehman, S., Guo, S. \& Hou, Y. Rational design of Si/SiO ${ }_{2} @$ Hierarchical porous carbon spheres as efficient polysulfide reservoirs for high-performance Li-S battery. Adv. Mater. 28, 3167-3172 (2016).

24. Seh, Z. W. et al. Two-dimensional layered transition metal disulphides for effective encapsulation of high-capacity lithium sulphide cathodes. Nat. Commun. 5, 5017 (2014).

25. El Jaroudi, O., Picquenard, E., Gobeltz, N., Demortier, A. \& Corset, J. Raman spectroscopy study of the reaction between sodium sulfide or disulfide and sulfur: identity of the species formed in solid and liquid phases. Inorg. Chem. 38, 2917-2923 (1999)

26. Li, L. et al. Phosphorene as a polysulfide immobilizer and catalyst in highperformance lithium-sulfur batteries. Adv. Mater. 29, 1602734 (2017).

27. Deng, D.-R. et al. Co4N nanosheet assembled mesoporous sphere as a matrix for ultrahigh sulfur content lithium-sulfur batteries. ACS Nano 11, 6031-6039 (2017).

28. Kumar, N., Raman, N. \& Sundaresan, A. Synthesis and properties of cobalt sulfide phases: $\mathrm{CoS}_{2}$ and $\mathrm{Co}_{9} \mathrm{~S}_{8}$. Z. Anorg. Allg. Chem. 640, 1069-1074 (2014).

29. Dong, J., Li, D., Peng, Z. \& Zhou, Y. Synthesis and electrochemical performanceof cobalt disulfide. J. Solid State Electrochem. 12, 171-174 (2008).

30. Richards, R. P., Clopton, E. L. \& Jaszczak, J. A. Pyrite and marcasite intergrowths from northern Illinois. Mineral. Rec. 26, 129-139 (1995).

31. Wei, S. et al. A stable room-temperature sodium-sulfur battery. Nat. Commun. 7, 11722 (2016)

32. Park, C.-W., Ahn, J.-H., Ryu, H.-S., Kim, K.-W. \& Ahn, H.-J. Roomtemperature solid-state sodium/sulfur battery. Electrochem. Solid State Lett. $\mathbf{9}$, A123-A125 (2006)

33. Yu, X. \& Manthiram, A. Performance enhancement and mechanistic studies of room-temperature sodium-sulfur batteries with a carbon-coated functional nafion separator and a Na2S/activated carbon nanofiber cathode. Chem. Mater. 28, 896-905 (2016).

34. Wenzel, S. et al. Thermodynamics and cell chemistry of room temperature sodium/sulfur cells with liquid and liquid/solid electrolyte. J. Power Sources 243, 758-765 (2013).

35. Lee, D.-J. et al. Alternative materials for sodium ion-sulphur batteries. $J$. Mater. Chem. A 1, 5256-5261 (2013).

36. Yao, Y. et al. Binding S0.6Se0.4 in $1 \mathrm{D}$ carbon nanofiber with $\mathrm{C} \square \mathrm{S}$ bonding for high-performance flexible Li-S batteries and $\mathrm{Na}-\mathrm{S}$ batteries. Small 13, 1603513 (2017). 
37. Yu, X. \& Manthiram, A. Capacity enhancement and discharge mechanisms of room-temperature sodium-sulfur batteries. ChemElectroChem 1, 1275-1280 (2014).

38. Kumar, V., Wang, Y., Eng, A. Y. S., Ng, M.-F. \& Seh, Z. W. A biphasic interphase design enabling high performance in room temperature sodiumsulfur batteries. Cell Rep. Phys. Sci. 1, 100044 (2020).

39. Kumar, V. et al. An artificial metal-alloy interphase for high-rate and long-life sodium-sulfur batteries. Energy Storage Mater. 29, 1-8 (2020).

40. $\mathrm{Li}, \mathrm{Z}$. et al. A 3D nitrogen-doped graphene/TiN nanowires composite as a strong polysulfide anchor for lithium-sulfur batteries with enhanced rate performance and high areal capacity. Adv. Mater. 30, 1804089 (2018).

41. Wang, Y.-X. et al. Achieving high-performance room-temperature sodium-sulfur batteries with S@interconnected mesoporous carbon hollow nanospheres. J. Am. Chem. Soc. 138, 16576-16579 (2016).

42. Sun, R., Chan, M. \& Ceder, G. First-principles electronic structure and relative stability of pyrite and marcasite: Implications for photovoltaic performance. Phy. Rev. B 83, 235311 (2011).

43. Mathew, K., Sundararaman, R., Letchworth-Weaver, K., Arias, T. \& Hennig, R. G. Implicit solvation model for density-functional study of nanocrystal surfaces and reaction pathways. J. Chem. Phys. 140, 084106 (2014).

44. Momida, H., Yamashita, T. \& Oguchi, T. First-principles study on structural and electronic properties of $\alpha-\mathrm{S}$ and Na-S crystals. J. Phys. Soc. Jpn. 83, 124713 (2014).

45. Zhang, Q. et al. Understanding the anchoring effect of two-dimensional layered materials for lithium-sulfur batteries. Nano Lett. 15, 3780-3786 (2015).

46. Kresse, G. \& Furthmüller, J. Efficient iterative schemes for ab initio totalenergy calculations using a plane-wave basis set. Phys. Rev. B 54, 11169-11186 (1996).

47. Blöchl, P. E. Projector augmented-wave method. Phys. Rev. B 50, 17953-17979 (1994).

48. Sun, J., Ruzsinszky, A. \& Perdew, J. P. Strongly constrained and appropriately normed semilocal density functional. Phys. Rev. Lett. 115, 036402 (2015)

49. Sun, J. et al. Accurate first-principles structures and energies of diversely bonded systems from an efficient density functional. Nat. Chem. 8, 831-836 (2016).

50. Peng, H., Yang, Z.-H., Perdew, J. P. \& Sun, J. Versatile van der Waals density functional based on a meta-generalized gradient approximation. Phys. Rev. X 6, 041005 (2016)

51. Sabatini, R., Gorni, T. \& De Gironcoli, S. Nonlocal van der Waals density functional made simple and efficient. Phys. Rev. B 87, 041108 (2013).

\section{Acknowledgements}

We appreciate the support from the National Natural Science Foundation of China (Nos. 21773188 and 21972111), Fundamental Research Funds for the Central Universities
(XDJK2019AA002), Postgraduate tutor team-building project (XYDS201911). The work at UT was supported by the Welch Foundation (F-1841) and the Texas Advanced Computing Center.

\section{Author contributions}

M.K. Aslam designed the project, conducting synthesis, and electrochemical tests. I.D. Seymour and N. Katyal did the DFT calculations. S. Li helped with the figures. T.T. Yang carried out the thermogravimetry experiments and purchased chemicals. G. Henkelman supervised the DFT calculations. S.J. Bao and M.W. Xu jointly supervised the project.

\section{Competing interests}

The authors declare no competing interests.

\section{Additional information}

Supplementary information is available for this paper at https://doi.org/10.1038/s41467 020-19078-0.

Correspondence and requests for materials should be addressed to G.H. or M.X.

Peer review information Nature Communications thanks Stefan Kaskel and the other anonymous, reviewer(s) for their contribution to the peer review of this work. Peer reviewer reports are available.

Reprints and permission information is available at http://www.nature.com/reprints

Publisher's note Springer Nature remains neutral with regard to jurisdictional claims in published maps and institutional affiliations.

\begin{abstract}
(c) ()
Open Access This article is licensed under a Creative Commons Attribution 4.0 International License, which permits use, sharing, adaptation, distribution and reproduction in any medium or format, as long as you give appropriate credit to the original author(s) and the source, provide a link to the Creative Commons license, and indicate if changes were made. The images or other third party material in this article are included in the article's Creative Commons license, unless indicated otherwise in a credit line to the material. If material is not included in the article's Creative Commons license and your intended use is not permitted by statutory regulation or exceeds the permitted use, you will need to obtain permission directly from the copyright holder. To view a copy of this license, visit http://creativecommons.org/ licenses/by/4.0/.
\end{abstract}

(C) The Author(s) 2020 